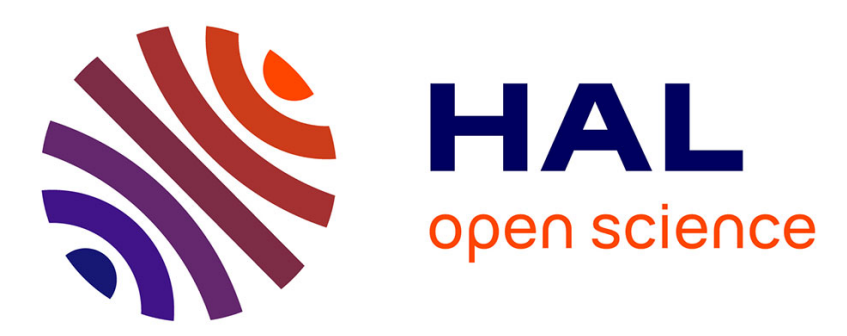

\title{
Enhancement of yield and persistence of perennial ryegrass inoculated with one endophyte isolate in France
}

Catherine Ravel, François Balfourier, Jean Jacques Guillaumin

\section{To cite this version:}

Catherine Ravel, François Balfourier, Jean Jacques Guillaumin. Enhancement of yield and persistence of perennial ryegrass inoculated with one endophyte isolate in France. Agronomie, 1999, 19 (7), pp.635344. hal-00885958

\author{
HAL Id: hal-00885958 \\ https://hal.science/hal-00885958
}

Submitted on 1 Jan 1999

HAL is a multi-disciplinary open access archive for the deposit and dissemination of scientific research documents, whether they are published or not. The documents may come from teaching and research institutions in France or abroad, or from public or private research centers.
L'archive ouverte pluridisciplinaire HAL, est destinée au dépôt et à la diffusion de documents scientifiques de niveau recherche, publiés ou non, émanant des établissements d'enseignement et de recherche français ou étrangers, des laboratoires publics ou privés. 


\title{
Original article
}

\section{Enhancement of yield and persistence of perennial ryegrass inoculated with one endophyte isolate in France}

\author{
Catherine Ravel $^{\mathrm{a}^{*}}$, François Balfourier ${ }^{\mathrm{a}}$, Jean Jacques Guillaumin ${ }^{\mathrm{b}}$ \\ a Unité d'amélioration des plantes, Inra, 234 avenue du Brézet, 63039 Clermont-Ferrand cédex 02, France \\ ${ }^{b}$ Unité de pathologie végétale et mycologie, Inra, 234 avenue du Brézet, 63039 Clermont-Ferrand cédex 02, France
}

(Received 13 March 1999; accepted 6 July 1999)

\begin{abstract}
The contribution of Neotyphodium endophytes to the performance of perennial ryegrass in Europe is poorly documented. The objective of this study was to compare the yield and persistence of three endophyte-infected (E.I.) and endophyte-free (E.F.) perennial ryegrass cultivars. The E.I. versions were obtained by artificial inoculation of each cultivar with one isolate of Neotyphodium belonging to the second taxonomic group (LpTG-2). The field experiment was carried out for a 3-year period at five different locations in France, three of which could be considered climatically stressful for perennial ryegrass. At all locations, the endophyte enhanced the productivity of each cultivar in the second year after sowing; moreover, it generally improved their persistence in stressful environments. These results show that endophyte infection can increase the ecological fitness of perennial ryegrass. Thus, plant breeders can use endophytes to improve perennial ryegrass, provided that the strains involved produce no or low levels of toxins dangerous for mammals. (@ 1999 Inra/Éditions scientifiques et médicales Elsevier SAS.)
\end{abstract}

agronomic performance / environmental stress / Lolium perenne / Neotyphodium endophyte / trial plots

Résumé - Rendement et persistance du ray-grass anglais inoculé avec un isolat d'endophyte en France. L'impact des endophytes du genre Neotyphodium sur les performances agronomiques du ray-grass anglais en Europe est encore mal connu. Une étude en plein champ a été réalisée sur une période de trois ans en cinq lieux (dont trois pouvant être considérés comme climatiquement stressants pour le ray-grass) afin de comparer trois variétés, chacune existant sous deux formes: porteuse d'endophyte (E.I.) et indemne (E.F.). Les versions E.I. ont été réalisées par inoculation artificielle des variétés avec une même souche de Neotyphodium appartenant au second groupe taxonomique des e-endophytes du ray grass-anglais (LpTG-2). Les résultats montrent que la présence de l' endophyte permet d'augmenter le rendement en matière sèche de la deuxième année d'exploitation de toutes les variétés et dans tous les lieux. La péren-

Communicated by Max Rives (Villeneuve-lès-Avignon, France)

* Correspondence and reprints

ravel@clermont.inra.fr 
nité des variétés est généralement améliorée par l'endophyte dans les environnements les plus stressants. Il semble donc possible d'utiliser la symbiose pour améliorer le ray-grass anglais à condition toutefois de disposer de souches hypotoxiques pour les mammifères. (C) 1999 Inra/Éditions scientifiques et médicales Elsevier SAS.)

performances agronomiques / Lolium perenne / Neotyphodium / essai en plein champ / stress environnemental

\section{Introduction}

Perennial ryegrass is one of the many grass species that can harbour symptomless endophytic fungi belonging to the Neotyphodium species (formerly Acremonium ). Based on morphology, ability to produce spores in vitro and isozyme patterns, two distinct groups of Neotyphodium can infect this host [8]: the first taxonomic goup (Lp-TG1) correspond to $N$. lolii, whereas the second taxonomic group (Lp-TG2) has not been given a Latin name.

Such associations involving grasses and Neotyphodium endophytes are mutualistic [9, 39]. The fungus grows intercellularly in the shoot of its host excluding leaf blades and totally depends on the plant for nutrition and dissemination (seed transmission). From a general point of view, Neotyphodium endophytes are reported to enhance the pest and stress tolerance of its host as well as its growth $[9,17,42]$.

The protective anti-herbivore effects of the endophytes are due to specific metabolites [9] such as lolitrems and ergopeptines acting particularly against mammals, and peramine and lolines acting against some insects. However, the production of mycotoxins greatly depends on the endophyte genotype [40].

Under controlled conditions, the tolerance of symbiotic plants of tall fescue or perennial ryegrass to abiotic stress has mostly been studied in cases of drought and nitrogen deficiency [2, 43]. In tall fescue/Neotyphodium endophyte associations, several mechanisms explain the improved drought tolerance of symbiotic plants such as their enhanced root growth [5], faster leaf-rolling [1], enhanced osmotic adjustment and the maintenance of turgor levels under water stress [14]. The nitrogen deficiency tolerance of symbiotic tall fescue seems to be improved by an increased activity of glutamine synthetase regardless of nitrogen level or form favouring the utilisation of nitrogen [27]. In perennial ryegrass/Neotyphodium endophyte associations, Ravel et al. [32] showed that endophyte infection could also improve the drought or nitrogen deficiency tolerance of perennial ryegrass clones. However, according to Lewis et al. [25], endophyte infection had few effects on Lolium perenne dry matter production even in the case of nitrogen deficiency. These authors explained their negative result by a probably too low $\mathrm{N}$ stress due to the conditions of the experiment performed with clones growing in flowing nutrient solution.

Under controlled environments, several studies have shown that endophyte presence tends to increase growth characteristics of tall fescue [ 1 , 11], perennial ryegrass [21] and meadow fescue [37]. However, the effects of endophyte on host plant growth are not consistent across host genotypes. It can also depend on the age of the plants and experimental conditions such as the nutrient level [7]. In the absence of stress, the higher growth of symbiotic plants could be explained by an increased efficiency of carbohydrate utilisation [18] and by a phytohormone-mediated response [43]. For example, auxin is a key hormone in regulating plant growth. As indol acetic acid (I.A.A.) production was shown for $N$. coenophialum in pure culture [10], the endophyte might be involved in auxin metabolism leading to an enhanced growth of symbiotic plants.

Under field conditions, it is expected that endophyte-infected (E.I.) cultivars would show better performance than endophyte-free (E.F.) cultivars. However, field comparisons between E.I. and E.F. cultivars gave contrasting results. For tall fescue, Siegel et al. [38] observed no difference in survival, herbage and seed yield between E.I. and E.F. populations in favourable environmental condi- 
tions, whereas Read and Camp [33] and Bouton et al. [6] reported that $N$. coenophialum enhanced growth and persistence in the same species under climatically stressful conditions. Similar results were reported for perennial ryegrass. In a cool, moist location in New Zealand, Neotyphodium endophyte had no effect on perennial ryegrass [12]. In France [31] and Spain [30], the effects of endophyte on the agronomic traits of this species depend on environmental conditions: the drier they are, the more important are the beneficial effects of the endophytes.

However, frequent interactions between endophyte infection and host plant genotypes, leading to contrasting results, are detected $[4-6,11,13$, $18,23,24,34]$. It seems that the beneficial effects of endophytes are the result of specific interactions between plant genotypes, endophyte isolates and environmental conditions. Therefore, extrapolating results obtained from clonal material under controlled conditions to heterogeneous populations in the field is difficult and field trials are required. Moreover, up to now, such interactions could be increased by the great variability of the material tested; in most experiments, the E.I./E.F. pairs consist of a genotype (or cultivar) with its native endophyte and the same genotype (or cultivar) deprived of its endophyte by selection or physical treatment. Such material can make it difficult to separate the effects of the genotypes of the plant and the fungus.

Although the French perennial ryegrass germplasms, especially in hot and dry areas, were found to be highly infected [26], up to now, little is known about the effects of endophyte infection upon agronomic performances of this host in French conditions. Moreover, studies reporting the effects of one particular endophyte strain in several cultivars or of several endophyte strains in only one plant genotype or cultivar are rare [22]. Therefore, this study was undertaken to investigate the effects of only one endophyte isolate on the growth and persistence of three perennial ryegrass cultivars at several French locations, whose climatic and soil conditions differed. This is the first time that the effects of one single endophyte isolate were studied on several cultivars.

\section{Materials and methods}

\subsection{Materials}

Three cultivars of perennial ryegrass were used in this study: Vigor, Parcour and Pacage. One-hundred seeds of each cultivars were microscopically examined for endophyte infection. As no endophyte was found, these cultivar were considered to be E.F. However, such a control did not allow the detection of a very low infection rate. Thus, to ensure that all the seeds to be used in the experiment were previously E.F., they were also subjected to a moderate heat treatment $[39,35]$, which kills the endophyte without affecting seedling vigour.

\subsubsection{E.I. material}

A total of 500 heat-treated seeds of each cultivar were used to produce axenic plantlets which were inoculated with one strain of endophyte. The endophyte strain used in this experiment was isolated from a French wild population of perennial ryegrass. Based on morphology and isozyme studies, it belonged to LpTG2 [8]. The inoculation was realised under sterile conditions using a method adapted from that reported by Latch and Christensen [20]: plants were inoculated by placing a drop of sterile water with ground mycelium in a slit at the junction of the mesocotyl and the coleoptile [29].

Two-month-old inoculated plants were examined for endophytes and re-isolation was carried out from all the plants considered to be E.I. All of them contained the LpTG-2 endophyte. For each cultivar, about 50 E.I. plants were obtained. These plants were then used in three different polycrosses (one per cultivar) to produce E.I. seeds. In these polycrosses, E.F. plants were planted with the E.I. plants. These E.F. plants were not harvested but only used as paternal parents to increase effective population size and thus avoid genetic drift and to maintain the allelic diversity of each cultivar. As LpTG-2 was $100 \%$ transmitted to the seeds of perennial ryegrass [29], all the seeds collected from each of 50 E.I. mother plants were E.I.

\subsubsection{E.F. material}

E.F. seeds consisted of heat-treated commercial seedlots. Consequently, for each cultivar, the only difference between E.F. and E.I. seedlots was the absence or presence of a single endophyte strain. 


\subsection{Trial plot experiment (figure 1)}

Each cultivar, with and without endophyte, was sown at five locations in France:

in September 1994, at Les Alleuds $\left(47^{\circ} 28^{\prime} \mathrm{N}\right.$, $0.33 \mathrm{~W})$, Orchies $\left(50^{\circ} 28^{\prime} \mathrm{N}, 3^{\circ} 15^{\prime} \mathrm{E}\right)$ and Rodez $\left(44^{\circ} 21^{\prime} \mathrm{N}, 2^{\circ} 34^{\prime} \mathrm{E}\right)$;

in April 1995, at Clermont-Ferrand $\left(45^{\circ} 47^{\prime} \mathrm{N}\right.$, $\left.3^{\circ} 05^{\prime} \mathrm{E}\right)$ and Verneuil l'Etang (48 $\left.32^{\prime} \mathrm{N}, 2^{\circ} 40^{\prime} \mathrm{E}\right)$.

The environmental conditions at each location are summarised in figure 1 . This figure gives the climatic data and the index of Turc [41] for each location. This index, based on several data characterising environmental conditions (climatic and edaphic data), allows us to estimate the potential forage production at every location. Such an index also depends on soil characteristics. It was calculated by taking into account the water reserve of different soils [28].
Each genotype with and without endophyte was sown in $5-\mathrm{m}^{2}$ plots, at a rate of $2.5 \mathrm{~g}$ seed. $\mathrm{m}^{-2}$, in a randomised block design with five replicates. Fertilisation was applied to the plots at each location according to current farming practices. Herbage yield was assessed at 4-week intervals using a plot harvester to cut and weigh herbage from each plot. A sub-sample of $1 \mathrm{~kg}$ of fresh herbage per plot was dried at $90{ }^{\circ} \mathrm{C}$ for $40 \mathrm{~h}$ and reweighed to determine the dry matter content. Such data was accumulated to obtain three seasonal (spring, summer and autumn) yields and annual yields for the first and second years following sowing. As summer and autumn yields were generally low, they were also cumulated. Moreover, a visual estimate of the stand was made on each plot in the third year following sowing. This trait was scored on a scale from 1 (ground area covered with perennial ryegrass inferior to $10 \%$; poor persistence of the plants in the plot) to 9 (percentage of ground area covered with perennial ryegrass superior to $90 \%$; very good persistence of the plants in the plot).

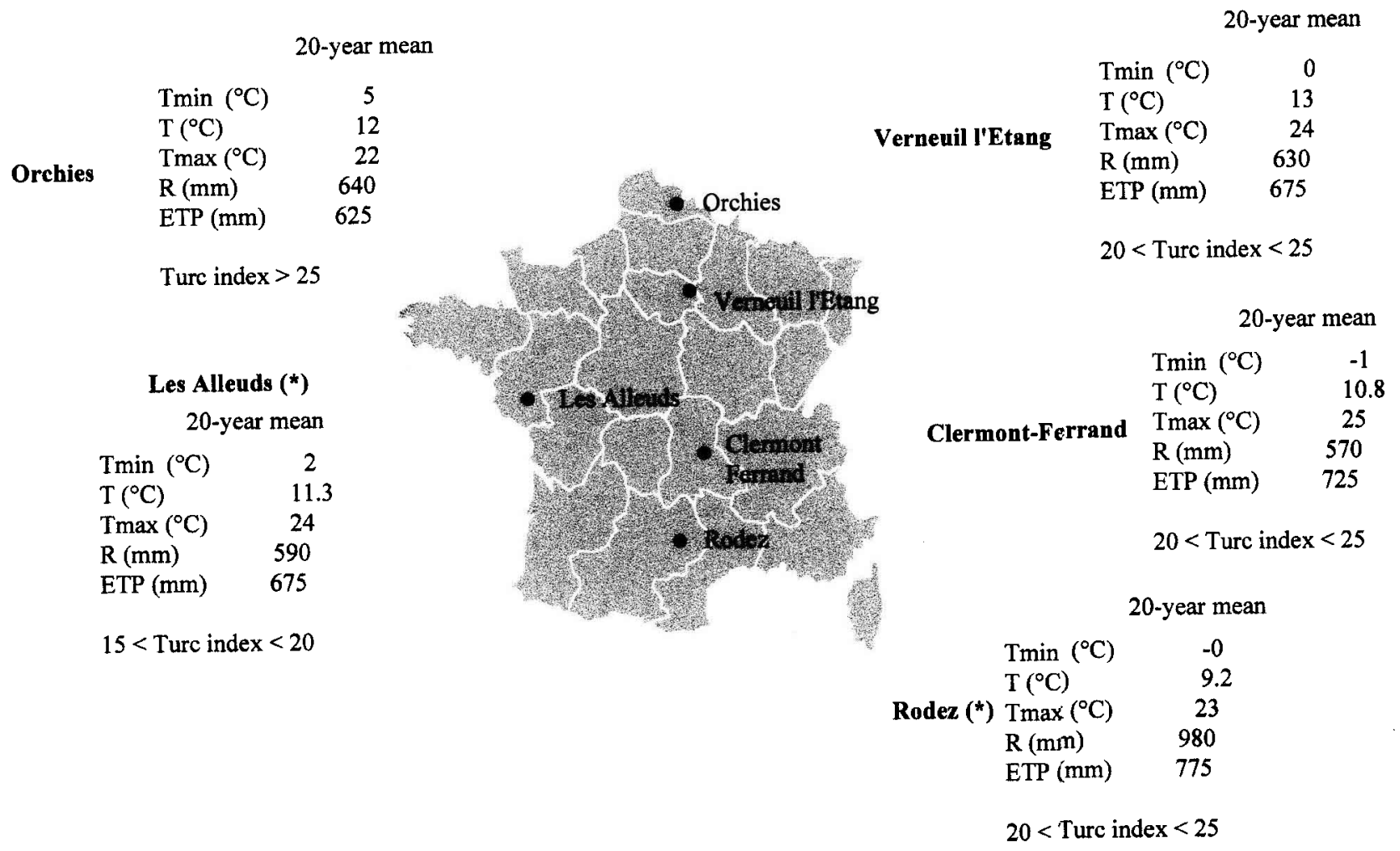

Figure 1. Locations and environmental conditions.

$\mathrm{T}=$ Mean annual temperature, Tmin = mean minimal temperature of the coldest month, Tmax = mean maximal temperature of the hottest month, $\mathrm{R}=$ annual rainfall and ETP = evapotranspiration from March to October.

High values of Turc's index indicate a high potentiel for forage production (favourable environmental conditions).

(*) indicates that the Turc's index is not established precisely. It is overestimated owing to an overestimation of the soil water reserve. (very low in these cases). 
To check whether the level of endophyte of each association fulfilled expectations (about 0 and $100 \%$ in E.F. and E.I. cultivars, respectively), at least 50 tillers per cultivar growing in the field were examined for the endophyte using the method described by Latch and Christensen [20] in the first and third years following sowing at each location except at Les Alleuds, where this control was carried out only in the first year following sowing. No discrepancy between expected and observed results was noted. The levels of infection observed remaining contrasted: $0 \%$ for E.F. cultivars and superior to $90 \%$ for E.I. cultivars.

\subsection{Statistical analysis}

Data were subjected to an analysis of variance with three main effects (location, cultivar and endophyte status) and all the interactions; the block effect was also introduced in the model as being nested to the location. Such an analysis was performed by the GLM procedure of SAS [36].

In the absence of interaction, as some data were missing, means for the main effect 'endophyte status' were compared by the method of Bonferroni.

\section{Results and discussion}

\subsection{Endophyte and yields}

As no interaction was significant for yield (table $l$ ), we interpreted the main effects. Location effects were highly significant $(P<0.001)$. Cultivar effects were significant for most traits $(P=0.05)$ with the exception of the total yield in the second year following sowing. The endophyte status effect was not significant for yields obtained in the first year following sowing $(P>0.05)$, whereas they were generally highly significant $(P=0.001)$ in the second year. The comparison of means ( table II) showed that, in the case of significant endophyte status effects, E.I. cultivars outyielded E.F. cultivars.

Endophyte infection is reported to improve dry matter yield and root growth under controlled conditions of tall fescue [1] and perennial ryegrass [21]. Moreover, although endophyte effects on agronomic characters of field-grown plants are less well documented than those observed in a con-

Table I. ANOVA of persistence and yield as influenced by trial location, cultivar genotype, endophyte infection and each interaction.

Mean squares

\begin{tabular}{lcccccccc}
\hline $\begin{array}{l}\text { Source of } \\
\text { variation }\end{array}$ & df & 1spring & $\begin{array}{c}\text { 1summer- } \\
\text { autumn }\end{array}$ & 1tot & 2spring & $\begin{array}{c}\text { 2summer- } \\
\text { autumn }\end{array}$ & 2tot & persistence \\
\hline $\begin{array}{l}\text { Location } \\
\text { block(location) }\end{array}$ & 4 & $11.424 * * *$ & $78.000 * * *$ & $374.79 * * *$ & $181.818 * * *$ & $81.953 * * *$ & $332.93 * * *$ & $44.773 * * *$ \\
geno & 2 & $0.260 * * *$ & $0.234 * *$ & $0.987 * *$ & $0.915 * * *$ & $0.166 * *$ & $1.280 * * *$ & $1.831 * *$ \\
endo & 1 & $0.909 * * *$ & 0.240 & $2.197 * *$ & $1.742 * * *$ & $0.591 * * *$ & 0.446 & $5.275 * *$ \\
geno*endo & 2 & 0.021 & 0.368 & 0.309 & $1.800 * *$ & $1.031 * * *$ & $5.550 * * * 24.031 * * *$ \\
location*endo & 4 & 0.067 & 0.171 & 0.227 & 0.623 & 0.063 & 0.653 & $3.126 * *$ \\
location*geno & 8 & 0.085 & 0.069 & 0.417 & 0.470 & 0.067 & 0.476 & 1.405 \\
location*geno*endo & 7 & 0.039 & 0.072 & 0.147 & 0.364 & 0.028 & 0.172 & 0.260 \\
error & 91 & 0.069 & 0.107 & 0.0442 & 0.176 & 0.070 & 0.0328 & 0.778 \\
\hline
\end{tabular}

Location, geno and endo correspond to the three main effects trial location, cultivar genotype and endophyte status, respectively. Block(location) corresponds to the block effect nested in the location.

$1 / 2$ spring, $1 / 2$ summer-autumn and $1 / 2$ tot correspond to the spring, summer-autumn and total yields (tDM.ha ${ }^{-1}$ ) produced in the first/second year following sowing, respectively.

$*, * *, * * *$ Significant effects at $0.05,0.01,0.001$ levels, respectively. 
Table II. Persistence and dry matter yields $\left(\mathrm{t} \mathrm{DM} \cdot \mathrm{ha}^{-1}\right)$ of E.I. and E.F. perennial ryegrass cultivars.

\begin{tabular}{|c|c|c|c|}
\hline & $\begin{array}{l}\text { Sping } \\
\text { yield }\end{array}$ & $\begin{array}{l}\text { Summer-autumn } \\
\text { yield }\end{array}$ & $\begin{array}{l}\text { Total } \\
\text { yield }\end{array}$ \\
\hline \multicolumn{4}{|c|}{ First year following sowing } \\
\hline E.I. & $5.12 \mathrm{a}$ & $3.44 \mathrm{a}$ & $8.56 \mathrm{a}$ \\
\hline E.F. & $5.25 \mathrm{a}$ & $3.16 \mathrm{a}$ & $8.42 \mathrm{a}$ \\
\hline \multicolumn{4}{|c|}{ Second year following sowing } \\
\hline E.I. & $4.68 \mathrm{a}$ & $2.10 \mathrm{a}$ & $6.78 \mathrm{a}$ \\
\hline \multirow[t]{2}{*}{ E.F. } & $4.24 b$ & $1.88 \mathrm{~b}$ & $6.12 \mathrm{~b}$ \\
\hline & & Persistence ${ }^{1}$ & \\
\hline \multicolumn{4}{|c|}{ Third year following sowing } \\
\hline E.I. & & 6.28 & \\
\hline E.F. & & 5.25 & \\
\hline
\end{tabular}

'Means followed by different letters were significantly different at $5 \%$ according to the Bonferroni $\mathrm{T}$ tests.

trolled environment, it is admitted that Neotyphodium endophytes of tall fescue and perennial ryegrass can improve the yields of their hosts, especially under environmentally stressful field conditions $[6,30,31]$. Therefore, from a general point of view, our results confirmed that endophyte presence improves perennial ryegrass dry matter yield in French conditions.

However, in the present study, E.F. cultivars outperformed E.I. ones in the second year following sowing, whereas endophyte did not influence the productivity of perennial ryegrass in the first year following sowing. The absence of effect of endophyte infection on perennial ryegrass productivity was reported by Lewis [23], Lewis and Clements [24] and Eerens et al. [12] in cool and moist environments. According to these authors, insufficiently stressful conditions could explain their results. The lack of stress may also explain the results obtained the first year following sowing in the present study. Regardless of the climatic conditions and the endophyte status, the drought tolerance of perennial ryegrass decreases over time because its roots become more superficial [15]. This implies that, in a similar environment, older plants can undergo more stress than younger plants. Therefore, the productivity of young plots is not influenced by endophyte infection because they may not be subjected to sufficient stress, whereas yield may be improved by symbiosis when plants become older and more susceptible to abiotic stresses.

\subsection{Endophyte and persistence}

Table $I$ shows that endophyte status $\times$ location and endophyte status $\times$ cultivar interactions were significant for persistence $(P<0.01$ and $P \cong 0.05$, respectively). Therefore, the effects of the endophyte on persistence mainly depend on plant genotype and environmental conditions.

As it was not possible to interpret the main factors, the mean of persistence per genotype and per location was plotted in figure 2 . This figure illustrates that the endophyte did not influence the persistence of any cultivar at Orchies while persistence was greatly enhanced by infection at Les Alleuds. At the three other locations, the effect of the endophyte on persistence depended on the cultivar: the persistence of Pacage and Parcour was enhanced by endophyte, whereas that of Vigor was not influenced by the infection.

Perennial ryegrass is susceptible to drought and hot temperature. As Orchies is characterised by the lowest maximal temperature and evapotranspiration and the highest Turc index of all the locations (figure 1 ), it can be assumed that the environmental conditions at this location are suitable for this species. The four other locations were characterised by more stressful climatic conditions (high evapotranspiration) which were modulated by soil characteristics (water stress was increased at Rodez by rendzine soils while it was decreased at Clermont-Ferrand by deep, black soils of Limagne). The low values of the Turc index estimated for these locations confirm that they are stressful (figure 1). This index was at its lowest at Les Alleuds. Thus, this location can be considered to be the most stressful location of the network.

Therefore, our results show that the Lp TG-2 endophyte could improve the persistence of peren- 

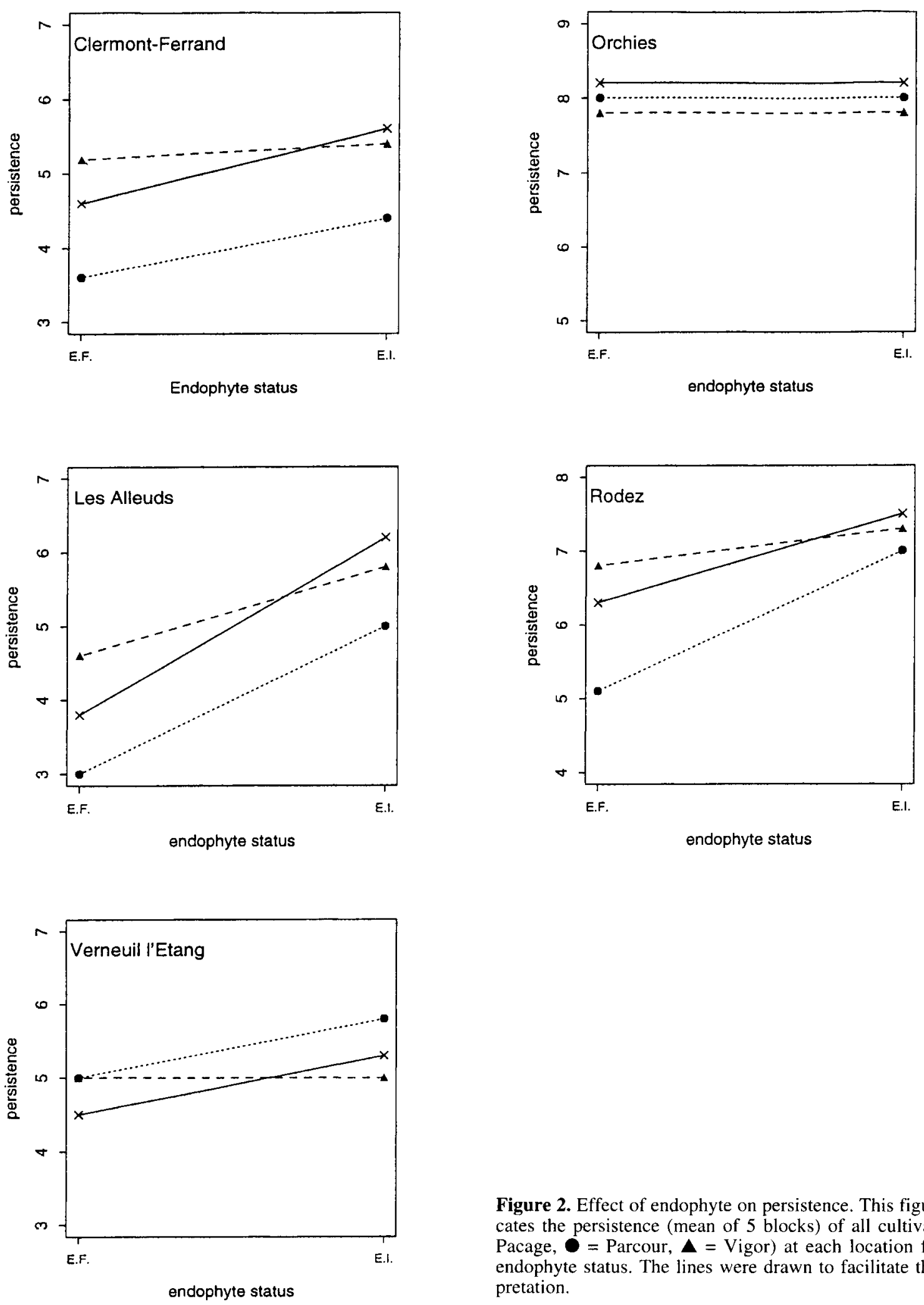

Figure 2. Effect of endophyte on persistence. This figure indicates the persistence (mean of 5 blocks) of all cultivars $(x=$ Pacage, $\boldsymbol{O}=$ Parcour, $\boldsymbol{\Delta}=$ Vigor) at each location for each endophyte status. The lines were drawn to facilitate the interpretation. 
nial ryegrass when the survival of its host is endangered while it did not influence the persistence of cultivars sown under more friendly environmental conditions. At locations characterised by moderately stressful conditions, endophyte could only benefit certain cultivars while the persistence of other cultivars was not influenced by the infection. Moreover, it is worth noting that the endophyte never altered the persistence of its host. Such a result confirms the importance of Neotyphodium endophytes in the survival of their host cultivated under stressful conditions [1, 6, 31, 44].

\section{Conclusion}

This study shows the beneficial effects of one strain of endophyte on field-performances of three perennial ryegrass cultivars. The commercial seeds, which were used for inoculation and establishment of E.F. plots, were heat-treated to ensure that seeds were endophyte-free. This treatment was gentle and it was verified that it did alter neither seed germination nor seedling vigour. Such a treatment was not applied to E.I. seeds after harvesting polycrosses because, in this case, it was important to conserve the endophyte alive. The population size used to re-create the E.I. version of each cultivar was considered to be sufficient to avoid genetic drift and allowed the allelic diversity to be maintained $[3,16,19]$. It can thus be considered that the E.I. seeds produced were genetically very close to their initial cultivar although not isogenic sensu stricto. Therefore, it is possible to conclude that the observed differences between E.I. and E.F. versions of a same cultivar were only due to the endophyte.

This study shows that the presence of endophyte can improve the productivity and persistence of three perennial ryegrass cultivars in French environmental conditions. The increased dry matter yield of E.I. cultivars may be linked to their enhanced persistence. However, the yields of E.I. cultivars in the second year following sowing were increased by the infection at all locations while their persistence was improved only in stressful locations. This result may indicate a direct effect of the endophyte used on the plant growth. Such a direct effect of endophytes on the productivity of Nui perennial ryegrass under field conditions, which were characterised by negligible levels of stresses (insect predation and drought), has already been hypothesised [22].

This study confirms the beneficial effect of endophyte productivity of field-grown perennial ryegrass even in French conditions. The beneficial effect of the endophyte on persistence is obvious under stressful environmental conditions only. Therefore, the utilisation of endophyte infection is a means for plant breeders to improve the adaptation of this species. Some E.I. cultivars can be developed for turfs without risk to cattle. However, for forage uses, the future of infected cultivars depends on the absence or the presence at low levels of anti-mammal mycotoxins. In the future, such a situation should change the ways of improving some grasses which harbour an Clavicipitaceous endophyte because breeders would have to take into account the selection of both partners.

Acknowledgments: The authors thank Dr Chosson (R.A.G.T.), Dr Bayle (Force Limagrain), Dr Bourdon (S.A. Carneau Frères) and Dr Baudouin (Verneuil Recherches) for providing evaluation data and helpful comments; and K. Lynch for improving the English style of this manuscript. This work was supported by a grant from the French Ministry of Agriculture.

\section{References}

[1] Arachevaleta M., Bacon C.W., Hoveland C.S., Radcliffe D.E., Effect of the tall fescue endophyte on plant response to environmental stress, Agron. J. 81 (1989) 83-90.

[2] Bacon C.W., Abiotic stress tolerances (moisture, nutrients) and photosynthesis in endophyte-infected tall fescue, Agric. Ecosyst. Environ. 44 (1993) 123-141.

[3] Balfourier F., Charmet G., Grand-Ravel C., Conservation of allelic multiplicity and genotypic frequency by pooling wild populations of perennial ryegrass, Heredity 73 (1994) 386-396.

[4] Belesky D.P., Stringer W.C., Hill N.S., Influence of endophyte and water regime upon tall fescue acces- 
sions. I. Growth characteristics, Ann. Bot. 63 (1995) 495-503.

[5] Belesky D.P., Fedders J.M., Does endophyte influence regrowth of tall fescue?, Ann. Bot. 78 (1996) 499-505.

[6] Bouton J.H., Gates R.N., Belesky D.P., Owsley M., Yield and persistence of tall fescue in the Southeastern coastal plain after removal of its endophyte, Agron. J. 85 (1993) 52-55.

[7] Cheplick G.P., Clay K., Marks S., Interaction between infection by endophytic fungi and nutrient limitation in the grasses Lolium perenne and Festuca arundinacea, New Phytol. 111 (1989) 89-97.

[8] Christensen M.J., Leuchtmann A., Rowan D.D., Tapper B.A., Taxonomy of Acremonium endophytes of tall fescue (Festuca arundinacea), meadow fescue ( $F$. pratensis) and perennial ryegrass (Lolium perenne), Mycol. Res. 97 (1993) 1083-1092.

[9] Clay K., Fungal endophytes of grasses: A defensive mutualism between plants and fungi, Ecology 69 (1988) 10-16.

[10] De Battista J.P., Bacon C.W., Severson R., Plattner R.D., Bouton J.H., Indole acetic acid production by the fungal endophyte of tall fescue, Agron. J. 82 (1990) 651-654.

[11] De Battista J.P., Bouton J.H., Bacon C.W., Siegel M.R., Rhizome and herbage production of endophyte-removed tall fescue clones and populations, Agron. J. 82 (1990) 651-654.

[12] Eerens J.P.J., Ryan D.L., Miller K.B., The ryegrass endophyte in a cool moist environment, Proc. $\mathrm{N}$. Z. Grassl. Assoc. 54 (1992) 157-160.

[13] Elbersen H.W., West C.P., Growth and water relations of field-grown tall fescue as influenced by drought and endophyte, Grass For. Sci. 51 (1996) 333-342.

[14] Elmi A.A., West C.P., Endophyte infection effects on stomatal conductance, osmotic adjustment and drought recovery of tall fescue, New Phytol. 131 (1995) 61-67.

[15] Gillet M., Les graminées fourragères, Bordas, Paris, 1980.

[16] Gregorius H.R., The probability of losing an allele when diploid genotypes are sampled, Biometrics 36 (1980) 643-652.

[17] Hill N.S., Ecological relationships of Balansiaeinfected graminoids, in: Bacon C.W., White J.F. Jr (Eds.), Biotechnology of Endophytic Fungi of Grasses, CRC Press, Boca-Raton, 1994, pp. 59-71.
[18] Hill N.S., Stringer W.C., Rottinghaus G.E., Belesky D.P., Parrott W.A., Pope D.D. Growth, morphological, and chemical component responses of tall fescue to Acremonium coenophialum, Crop Sci. 30 (1990) 156-161.

[19] Kimura M., Crow J.F., The number of alleles that can be maintained in a finite population, Genetics 111 (1964) 725-738.

[20] Latch G.C.M., Christensen M.J., Artificial infection of grasses with endophytes, Ann. Appl. Biol. 107 (1985) 17-24.

[21] Latch G.C.M., Hunt W.F., Musgrave D.R., Endophytic fungi affect growth of perennial ryegrass, N. Z. J. Agric. Res. 28 (1985) 165-168.

[22] Latch G.C.M., Hume D.E., Simpson W.R., Burton V.M., Plant growth can be affected by the strain of endophyte, in: Weideman G. (Ed.), Tall Fescue Toxicosis Workshop, SERAIEG-8, Nashville, 1998, p. 27.

[23] Lewis G.C., Herbage yield of nine genotypes of perennial ryegrass with and without infection by ryegrass endophyte, Ann. Appl. Biol. 116 (1990) 108-109.

[24] Lewis G.C., Clements R.O., Effect of Acremonium lolii on herbage yield of Lolium perenne at three sites in the United Kingdom, Proc. Int. Symposium on Acremonium / grass interactions, 1990, pp. 160-162.

[25] Lewis G.C., Bakken A.K., Macduff J.H., Raistrick N., Effect of infection by endophytic fungus Acremonium lolii on growth and nitrogen uptake by perennial ryegrass (Lolium perenne) in flowing solution culture, Ann. Appl. Biol. 129 (1996) 451-460.

[26] Lewis G.C., Ravel C., Naffaa W., Astier C., Charmet G., Occurrence of Acremonium endophytes in wild populations of Lolium spp. in European countries and a relationship between level of infection and climate in France, Ann. Appl. Biol. 130 (1997) 227-238.

[27] Lyons P.C., Evans J.E., Bacon C.W., Effects of the fungal endophyte Acremonium coenophialum on nitrogen accumulation and metabolism in tall fescue, Plant Physiol. 92 (1990) 726-732.

[28] Mori A., Turc L., Carte de France de potentialité fourragère annuelle en absence d'irrigation, Inra, Service d'étude des sols et de la carte pédologique de France, 1983.

[29] Naffaa W., Astier C., Ravel C., Guillaumin J.J., Creation of stable associations between perennial ryegrass or tall fescue and fungal endophytes, Agronomie 19 (1999) 133-144. 
[30] Oliveira A., Rottinghaus G.E., Collar J., Castro P., The perennial ryegrass endophyte in Galicia (Northwest Spain), J. Agric. Sci. 129 (1997) 173-177.

[31] Ravel C., Charmet G., Balfourier F., Influence of the fungal endophyte Acremonium lolii on agronomic traits of perennial ryegrass in France, Grass Forage Sci. 50 (1995) 75-80.

[32] Ravel C., Courty C., Coudret A., Charmet G., Beneficial effects of Neotyphodium lolii on the growth and the water status in perennial ryegrass cultivated under nitrogen deficiency or drought stress, Agronomie 17 (1997) 173-181.

[33] Read J.C., Camp B.J., The effect of the fungal endophyte Acremonium coenophialum on animal performance, toxicity and stand maintenance, Agron. J. 78 (1986) 848-850.

[34] Richardson M.D., Hoveland C.S., Bacon C.W., Photosynthesis and stomatal conductance of symbiotic and non symbiotic tall fescue, Crop Sci. 33 (1993) 145-149.

[35] Rolston M.P., Rowarth J.S., Aspects of endophyte in ryegrass (Lolium perenne) seed production, Proc. 3rd Int. Herbage Seed Conference, 1995, pp. 433-437.

[36] SAS Institute Inc., SAS/STAT User's Guide, Version 6, Fourth Edition, SAS Institute Inc., Cary, 1989.

[37] Schmidt D., Effects of Acremonium uncinatum and a Phialophora-like endophyte on vigour, insect and disease resistance of meadow fescue, Proc 2 nd Int. Symp. Acremonium/Grass Interactions, 1993, p. 185.

[38] Siegel M.R., Johnson M.C., Varney D.R., Nesmith W.C., Buckner R.C., Bush L.P., Burrus P.B., Jones T.A., Boling J.A., A fungal endophyte in tall fescue: incidence and dissemination, Phytopathology 74 (1984) 932-937.

[39] Siegel M.R., Latch G.C.M., Johnson M.C., Fungal endophytes of grasses, Ann. Rev. Phytopathol. 25 (1987) 293-315.

[40] Siegel M.R., Latch G.C.M., Bush L.P., Fannin F.F., Rowan D.D., Tapper B.A., Bacon C.W., Johnson M.C., Fungal endophyte-infected grasses: alkaloid accumulation and aphid response, J. Chem. Ecol. 16 (1990) $3301-3315$.

[41] Turc L., Indice climatique de potentialité agricole, Sciences du sol 2 (1972) 81-102.

[42] Van Heeswijck R., Mac Donald G., Acremonium endophytes in perennial ryegrass and other pasture grasses in Australia and New-Zealand, Austr. J. Agric. Res. 43 (1992) 1683-1709.

[43] West C.P., Physiology and drought tolerance of Endophyte-infected grasses, in: Bacon C.W., White J.F. Jr (Eds.). Biotechnology of Endophytic Fungi of Grasses, CRC Press, Boca-Raton, 1994, pp. 87-102.

[44] West C.P., Izecor E., Turner K.E., Elmi A.A., Endophyte effects on growth and persistence of tall fescue along a water-supply gradient, Agron. J. 85 (1993) 267-270. 